\title{
MORPHODYNAMIC INSTABILITIES IN THE SURF ZONE
}

\author{
SANDRA FACHIN \\ DHA, National Civil Engineering Laboratory/LNEC, Av. Brasil, 101 \\ Lisbon, 1700-066, Portugal \\ FRANCISCO E. P. SANCHO \\ DHA, National Civil Engineering Laboratory/LNEC, Av. Brasil, 101 \\ Lisbon, 1700-066, Portugal
}

\begin{abstract}
The bed forms in the surf zone can grow as a result of natural morphodynamic instabilities, forced by the wave-induced flow. This work gives a contribution to the dynamics of the formation and evolution the bed forms in surf zone. We use the new morphodynamic model, M-SHORECIRC, to analyze the growth and dynamics of bar-type, rhythmic, bed forms of a barred beach. These analyses include the effects of initial wave angle, wave energy, and bar location. These are all seen to influence the dynamics of the rhythmic bed-forms regarding the longshore length-scales, and intensity and location of bed-forms.
\end{abstract}

\section{Introduction}

The formation and migration of sandbars is an important element in the morphological processes that are responsible for changes in beach profiles. The unconsolidated sediments are arranged by wave action into a set of morphological patterns. Close to the shoreline, the most common forms are sandbars, which, typically, are shore parallel, but can also be rhythmic or grow into irregular shoals. This feature has an important and dynamic paper in local hydrodynamics and in the form and protection of the beach. The interactions between the morphology of the bottom and the hydrodynamics explain the formation and migration of bed features and different approaches has been used for the understanding of this.

Several studies show that the nearshore bed-forms can grow as a result from a natural (instability) mechanism, triggered by the nearshore hydrodynamics. Examples are those of Christensen et al. (1994), Falqués (1996), Caballeria et al. (2002) and Fachin \& Sancho (2004) for planar beaches, and of Deigaard et al. (1999), Damgaard et al (2002) and Calvete et al. (2002) for barred beaches. 
This work focus on the physical mechanisms involved in the dynamics of the formation and movement of bed forms (bars and shoals) in the surf zone of a barred beach. In particular, we study the effects of the initial wave angle, wave energy, and bar location in the bed forms using the morphodynamic model M-SHORECIRC.

\section{M-SHORECIRC: Morphodynamic Model}

The Quasi-3D morphodynamic model, M-SHORECIRC (Fachin \& Sancho, 2004) is an extension of the SHORECIRC model (Svendsen et al., 2001). It includes a sediment transport module for the estimation of the sediment transport rates forced by current-only or combined wave-current flows, and a morphodynamic module to compute the bed level changes of non-cohesive sediments. The MSHORECIRC is a process-based morphodynamic model and, thus, includes the interaction between hydrodynamic conditions, sediment transport and bed evolution. This means that the hydrodynamics - waves and currents - adjust to the changing bed morphology, which in turn develops as a function of the hydrodynamics and sediment fluxes. This model considers the effect of longitudinal and transverse bed slope and consists of three main modules, described in detail below.

\subsection{Hydrodynamic Model}

The hydrodynamic model SHORECIRC (Svendsen et al., 2001) solves the 2DH mass and momentum conservation equations in the time domain. It can also include the effect of the vertical variation of the horizontal velocities, which result from the interaction between time-averaged waves and currents. The circulation is forced by the mass flow and radiation stresses that are generated by the movement the waves propagating (and dissipating) towards the shore, which are calculated by the short-wave model REF/DIF (Kirby \& Darlrymple, 1994). This model accounts for combined effects of bottom induced refractiondiffraction, current induced refraction, and wave breaking dissipation.

The theory of SHORECIRC is defined in Putrevu \& Svendsen (1999) and Svendsen et al. (2001). The depth-integrated, short-wave-averaged equations can be derived from the Reynolds equations for conservation of mass and momentum.

The model equations contemplate the nonlinear interactions between waves and currents, and can be used to analyze coastal circulation over a previously defined bathymetry. Some hydrodynamic phenomena that have been modeled are surf beat, infragravity waves, shear waves and rip currents. 


\subsection{Sediment Transport Model}

Presently, the M-SHORECIRC model calculates the sediment transport as given by Soulsby \& Van Rijn, (in Soulsby, 1997):

$$
q t=A_{S} \bar{V}\left[\left(\bar{V}^{2}+\frac{0.018}{C_{D}} U_{r m s}^{2}\right)^{1 / 2}-\bar{U}_{c r}\right]^{2.4}(1-1.6 \tan \beta) .
$$

In the equation above, $q t$ is the volumetric transport rate; $V$ is the depthaveraged current velocity; $U_{r m s}$ represents the root-mean-square wave orbital velocity; $C_{D}$ is the drag coefficient (due to current alone); $U_{c r}$ is the threshold current velocity of motion (Van Rijn method) and $A$ s incorporates the combined bed-load and suspended load contributions and is defined in Soulsby (1997). The final term $(1-1.6 \tan \beta)$ represents the effect of the bed slope on the transport, which is an artifice commonly used by mathematical and numerical modelers, but is a less correct procedure than modifying the threshold velocity for slope effects.

This formula applies to the total sediment transport in combined waves and currents, on horizontal and sloping beds. The total transport rate results from the addition of bed load to suspended load. Transport due to the wave asymmetry and depth-varying currents are not accounted for.

The sediment flux is assumed aligned with the current. Thus, the sediment transport vector, in two coordinates, can be written as:

$$
q=\left(q_{x}, q_{y}\right)=\left(|q| \frac{V_{x}}{|V|},|q| \frac{V_{y}}{|V|}\right),
$$

where $q_{x}, q_{y}$ are the components of the sediment transport rates in the orthogonal $x, y$ directions; $V=\left(V_{x}, V_{y}\right)$ is the current velocity vector.

This type of models cannot predict sand transport rates opposite to the direction of the largest velocity, caused by large phase lags. The formula is intended for conditions in which the bed is rippled, and thus, the bottom roughness, $z_{0}$, is set equal to $6 \mathrm{~mm}$. Thus, it should be used with caution in cases where the bed is not rippled (Soulsby, 1997). On barred beaches, sheet flow conditions are often found over the bar and at the swash, whereas bed ripples (small and large) are found at the shoreface and in the trough behind the bar. For the present application, it is assumed that within the surf-zone the bed regime corresponds mainly to rippled bed. 


\subsection{Morphodynamic Model}

In the morphological module, bed-level variations due to gradients in the sediment transport are computed. The rate of bed level changes is determined from the equation for conservation of mass for the sediments, using the instantaneous sediment transport rates. The values of the transport rates are calculated at each point of the computational domain and at each morphological time step, using the current velocities obtained from the hydrodynamic model. The sediment budget equation, in two dimensions, can be written as:

$$
\frac{\partial z}{\partial t}=-\frac{1}{1-\lambda}\left(\frac{\partial q_{x}}{\partial x}+\frac{\partial q_{y}}{\partial y}\right)
$$

where $\mathrm{z}(\mathrm{x}, \mathrm{y}, \mathrm{t})$ is the bed level; $\partial \mathrm{z} / \partial \mathrm{t}$ is the rate of change of bed level; $\lambda$ is the porosity of bed material.

The time integration of the sediment conservation equation leads to the new bed configuration with which a new flow field is calculated. The time-step $\Delta \mathrm{t}$ is chosen in a case-to-case basis, satisfying Courant number (numerical) constraints, and avoiding significant bed changes within one time step.

\subsection{Algorithmic implementation}

The M-SHORECIRC solves the governing equations over a rectangular grid, using a finite difference method. Different schemes are applied to different submodules. The hydrodynamic part makes use of a $3^{\text {rd }}$-order (in time) scheme, whereas, at the present stage, the bed-level equation is solved by a simple Euler time-step integration. The morphological time-step is independent of the hydrodynamic time-step, as different numerical schemes apply. Different ratios between the two are applied.

\section{Study of surf zone instabilities in a barred beach}

In the following, the M-SHORECIRC model is applied to study the dynamics of the formation and movement of bed forms (bars and shoals) in the surf zone of a barred beach. We consider the initial bed profile as given by Calvete $e t$ al. (2002) that can be seen in Figure 1. It represents an equilibrium bottom profile of a rectilinear coastline, with an alongshore uniform bar at the surf zone. It is an exponential profile, with a slope at the shoreline equal to $\beta=0.03$. The initial bathymetry is uniform in the alonghore direction, and the bar distance to the shore, $\mathrm{Xb}$, is either $40 \mathrm{~m}$ or $70 \mathrm{~m}$. 


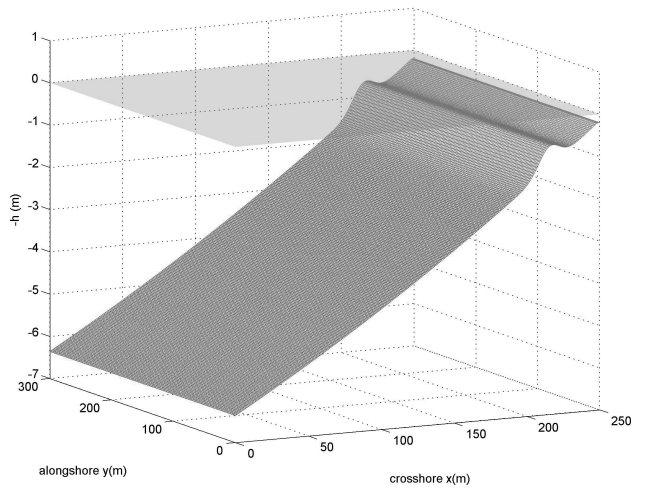

Figure1. Initial bathymetry with a uniform bar at $\mathrm{Xb}=40 \mathrm{~m}$.

The present computational domain has an extension $\mathrm{Lx}=250 \mathrm{~m}$ in the cross-shore direction, and $\mathrm{Ly}=300 \mathrm{~m}$ along the shore. The $\mathrm{x}$-coordinate is oriented towards the shore, and the y-coordinate is parallel to the shore. The domain is divided in spaced nodes, corresponding to $\Delta \mathrm{x}=1.0 \mathrm{~m}$ and $\Delta \mathrm{y}=2.0 \mathrm{~m}$. At the shoreline, a vertical wall is imposed with depth equal to $0.2 \mathrm{~m}$. At the offshore boundary with depth equal to $6.36 \mathrm{~m}$, an absorbing-generating boundary condition is considered, allowing (long) waves to enter and exit the domain, freely. As the beach is alongshore uniform, we specify a condition of periodicity at the lateral (cross-shore) boundaries. The morphological time-step $\left(\Delta \mathrm{t}_{\mathrm{m}}\right)$ is usually set to ten times the hydrodynamic time-step $\left(\Delta \mathrm{t}_{\mathrm{H}}\right)$.

In our simulations, a zero-velocity initial condition (cold start), at every grid-point, is assumed. The hydrodynamic module is iterated with the initial bathymetry being fixed until a nearly steady-state condition is reached. Upon this (nearly) equilibrium is reached, the cross- and alongshore sediment transport rates are computed in the sediment transport model, and the bed levels are updated according to the sediment continuity equation.

The hydrodynamic step includes computing the wave field, wave radiation stresses and volume fluxes and, hence, obtaining the longshore and cross-shore velocities and mean surface elevation. Since wave-current refraction is not significant in the present simulations, wave-current interaction is not included here. Furthermore, we neglect in the present tests the vertical variation of the horizontal currents. That is, we consider the $2 \mathrm{DH}$ hydrodynamic model equations, with an enhanced turbulent mixing in order to simulate shear dispersion. 
The different combinations of initial conditions and relations between morphological and hydrodynamical time-steps used in our tests can be seen in Table 1.

Table 1. Morphological and hydrodynamic initial conditions and parameters used in different combinations for the test cases

\begin{tabular}{|c|c|c|c|c|c|}
\hline $\begin{array}{l}\text { Morphodynamic } \\
\text { Time step }\left(\Delta t_{m}\right)\end{array}$ & Undertow & $\begin{array}{l}\text { Wave } \\
\text { height }\end{array}$ & $\begin{array}{l}\text { Wave } \\
\text { period }\end{array}$ & $\begin{array}{l}\text { Wave } \\
\text { angle }\end{array}$ & $\begin{array}{c}\text { Initial Bar properties } \\
\mathbf{X b} / \mathbf{w b} / \mathbf{h}(\mathbf{x b}) / \mathbf{A b}\end{array}$ \\
\hline $5 \Delta t_{H}$ & With & $1.0 \mathrm{~m}$ & & $0^{\circ}$ & $40 \mathrm{~m} / 10 \mathrm{~m} / 0.62 \mathrm{~m} / 0.5 \mathrm{~m}$ \\
\hline $10 \Delta t_{H}$ & and & & $6 s$ & & \\
\hline $20 \Delta t_{H}$ & Without & $0.5 \mathrm{~m}$ & & $15^{\circ}$ & $70 \mathrm{~m} / 15 \mathrm{~m} / 0.95 \mathrm{~m} / 1 \mathrm{~m}$ \\
\hline \multicolumn{6}{|c|}{ Hydrodynamic model parameter (in all cases): } \\
\hline \multicolumn{6}{|c|}{ Kappa $=0.78 ;$ gamma $=0.4 ; \mathrm{fcw}=0.01 ;$ vtshear $=0.2 ;$ mdiss $=0.1 ; \mathrm{Cs}=0.1$} \\
\hline \multicolumn{6}{|c|}{ Morphodynamical Model parameter (in all cases): } \\
\hline \multicolumn{6}{|c|}{$\rho \mathrm{s}=2650 \mathrm{~kg} \cdot \mathrm{m}-3 ; \mathrm{d} 50=0.25 \mathrm{~mm}, \mathrm{~d} 90=0.50 \mathrm{~mm} ; \mathrm{z} 0=0.006 \mathrm{~m}, v=1.36 * 10-6 \mathrm{~m} 2 \mathrm{~s}-1$} \\
\hline
\end{tabular}

\section{Results and discussion}

In order to check the influence of the numerical effects in our results, and thus assure the results reveal physically-induced and not numerically-induced bed variations, three simulations using different ratios between the morphodynamic and the hydrodynamic time step (see Table 1) were performed. For the start of the simulations, the initial bottom configuration, with a bar at $\mathrm{Xb}=40 \mathrm{~m}$, was perturbed with a random roughness with a maximum of $\pm 5 \mathrm{~mm}$ over the bed.

The results for the three simulations showed that after some time, rhythmic bed-patterns developed on the top of the bar, with erosion and accretion spots (alike transverse bars) over the longshore bar. Figure 2 shows a detail of the bed-level variation (final minus initial depth, erosion in light colors and accretion in dark) after 2 hours for the case with $\Delta \mathrm{t}_{\mathrm{m}}=10 \Delta \mathrm{t}_{\mathrm{H}}$. Meandering currents and circulation cells flow (in the wave-period time-averaged sense) over this bed configuration. The flow is mainly shoreward over the shoals and seaward in the troughs, forming a (periodic) rip current pattern, spaced approximately each $25 \mathrm{~m}$ apart.

The computations revealed that identical patterns were formed for the three ratios between morphological and hydrodynamical time-steps. Indeed, the details of the bed-pattern for each simulation are slightly different, as the system is highly non-linear and dynamical, which results from being a physical 
instability mechanism that triggers the growth of bed patterns. Therefore, we conclude that the morphodynamic model with the present parameters is stable and produces realistic results.

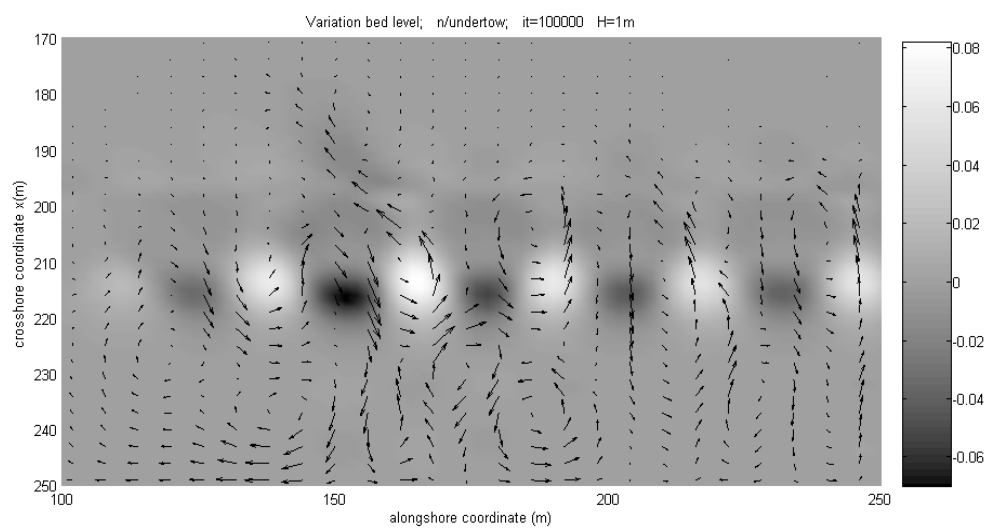

Figure 2. Bed level variation and instantaneous circulation pattern after $+/$-2hours for the computation with incident waves: $\mathrm{H}=1.0 \mathrm{~m}, \mathrm{~T}=6 \mathrm{~s}, \theta=0^{\circ}, \mathrm{Xb}=40 \mathrm{~m}$ and $\Delta \mathrm{tm}=10 \Delta \mathrm{tH}$. Erosion in light colors and accretion in dark.

\subsection{Undertow effect}

In a recent study, Fachin \& Sancho (2004) simulated the effect of accounting for the undertow, in a simplified manner, in the sediment transport flux. Those authors showed the growth of a quasi-uniform longshore bar (with periodic variations) from an initially plane bed (non-barred), when including the undertow.

Here, the same process is included in order to verify the effect the undertow has on the pre-existent longitudinal bar and development of bed forms. The undertow is estimated as the wave-induced volume flux, divided by the local depth. The total velocity that enters the sediment transport flux computation (eq. 2) is then corrected taking into account the undertow value.

Figure 3 shows the results for the computations with $\mathrm{H}=1.0 \mathrm{~m}, \mathrm{~T}=6 \mathrm{~s}, \theta=0^{\circ}$, with and without including the undertow (right and left, respectively). The top plots in the Figure correspond to the bottom configuration at the initial and end of the simulation. In both computations, the development of nearshore transverse bars at the location of the initial longshore bar is seen.

When including the undertow, it is observed a significant seaward movement of the longshore bar. This means that the inclusion of the undertow in the sediment transport formula changes appreciably the distribution of the 
sediment fluxes across the shore, hence, changing the convergence and divergence patterns of the sediments and net balance of bed variations.
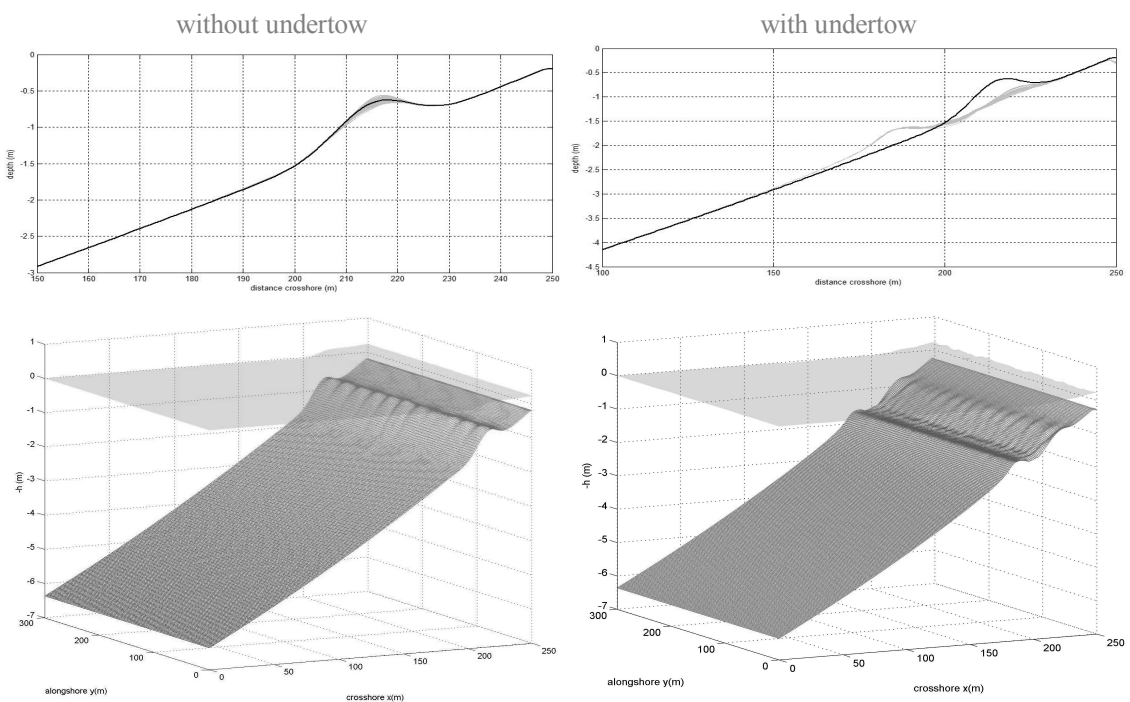

Figure 3. Initial and final bed configurations for the case where $\mathrm{H}=1 \mathrm{~m}, \mathrm{~T}=6 \mathrm{~s}, \theta=0^{\circ}$ and $\mathrm{Xb}=40 \mathrm{~m}$, with (right) and without (left) undertow. Top figures: initial profile (gray), final profile (black).

In the case where the undertow is not included, there is no offshore bar migration, but only the redistribution of sediment around and over the alongshore bar with periodical shoals and rip channels in the alongshore direction.

The results further evidence that the inclusion of the undertow induces stronger bed variations, which are caused by stronger effects of the wave and current hydrodynamics (a more intense circulation).

\subsection{Wave angle effect}

It is worth evaluating the influence of the incident wave angle in the development of bed forms. In order to isolate these effects, we use the simple 2DH model, i.e., the undertow effect is not included.

A comparison between the results for both normal and oblique incident wave angles is presented in Figure 4. For both results the wave height is $\mathrm{H}=0.5 \mathrm{~m}, \mathrm{~T}=6 \mathrm{~s}$ and $\mathrm{Xb}=40 \mathrm{~m}$. 
a)

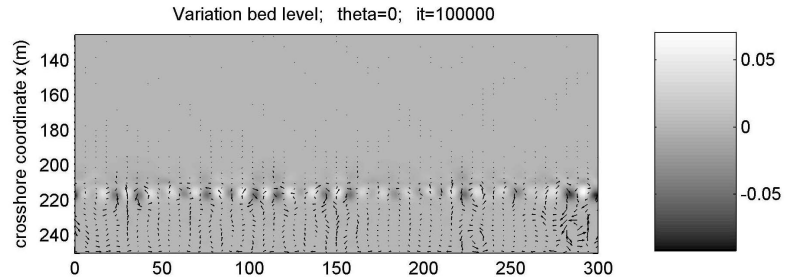

b)
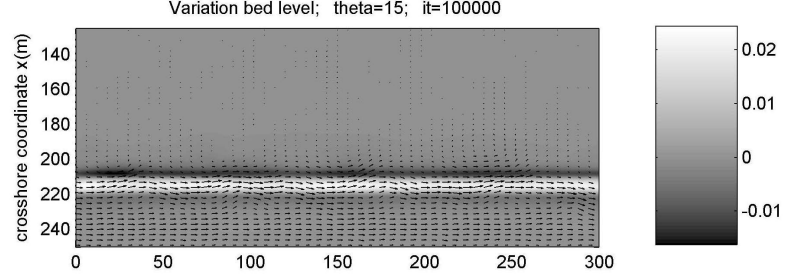

c)
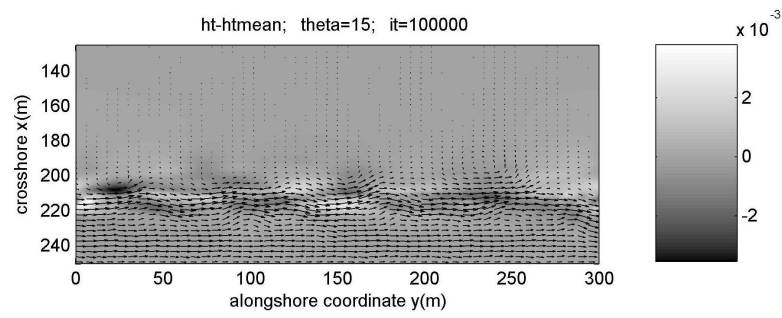

Figure 4. Bed variations and instantaneous current velocities (at $\mathrm{t}=2 \mathrm{hr}$ ): a) Normal-incident waves $\left(\theta=0^{\circ}\right)$; b) obliquely-incident waves $\left.\left(\theta=15^{\circ}\right) ; \mathrm{c}\right)$ bed variations from longitudinal-averaging of the final topography for the obliquely-incident waves $\left(\theta=15^{\circ}\right)$.

For normal incident waves one can observe the growth of small (height $<5 \mathrm{~cm}$ ), rhythmic bed patterns, closely spaced, over the longshore bar. It can also be seen a weak cross-shore current, and both left- and right-direct weak longhsore currents.

For the oblique waves, rhythmic bed forms have also developed, but are nearly undistinguishable from a slight shift of the initial longshore bar (Figure 4b). The flow is predominantly along the shore, with minor current oscillations (shear waves). The final periodic bed patterns for this computation are better isolated by subtracting the longitudinally-averaged mean (cross-shore) profile from the final bathymetry (Figure 4c). Indeed, the transverse bar pattern seen in the top panel for $\theta=0^{\circ}$ gives rise to an oblique bar pattern (lower panel) for $\theta=15^{\circ}$. With oblique waves, the $3 \mathrm{D}$ bed forms are transported (migrate) by the longshore current, but with a much smaller velocity. There is also a tendency 
for a slight onshore migration (which is clearer in computations with larger wave heights, not shown here).

\subsection{Wave energy and bar location effect}

To study the influence of the incident wave energy and bar location in the bed configurations, we did tests using two wave heights $(\mathrm{H}=0.5$ and $1.0 \mathrm{~m})$ and two bar locations and dimensions $(\mathrm{Xb}=40$ and $70 \mathrm{~m}$ from the shoreline). The simulations presented below are obtained without accounting for the undertow, and for normally incident waves. The role of the wave height (wave energy) and bar location is associated the location of the breaking point and energy dissipation relative to the beach.

The left two figures correspond to the narrower surfzone width, with intense breaking before or at the bar, whereas the right two figures represent the case with a wider crest-to-shoreline distance and breaking at the bar or past the bar and nearer the shore.

The initial bed configuration and breakpoint location for the four combinations of these parameters is given in Figure 5.

a)

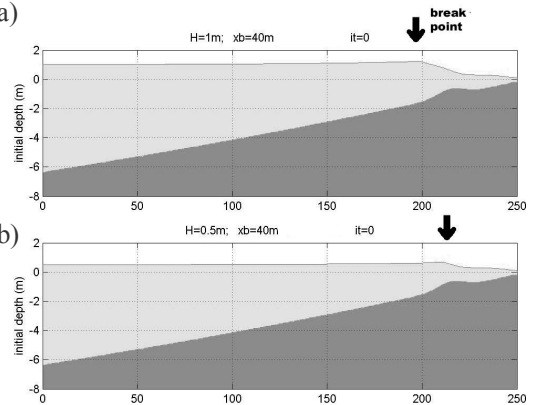

c)

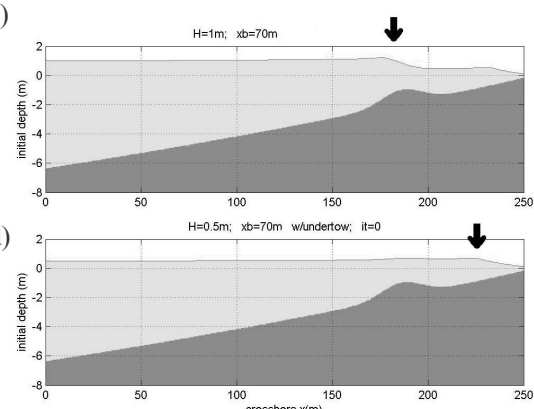

Figure 5. Initial bottom configuration and breakpoint location for model simulations, in a) and b) are the results for $\mathrm{Xb}=40 \mathrm{~m} ; \mathrm{c}$ ) and $\mathrm{d}$ ) are for $\mathrm{Xb}=70 \mathrm{~m}$. The upper panels correspond to $\mathrm{H}=1.0 \mathrm{~m}$ and the lower ones to $\mathrm{H}=0.5 \mathrm{~m}$.

The results show that the shoreline distance of the alongshore sandbar (Figure 6) affects the hydrodynamic pattern which controls the growth rate of the bed forms, creating a different bathymetric evolution (both in time and spatial configuration) in each situation. These results demonstrate that when the breakpoint distance is greater than the crest-to-shoreline distance (Xbr $>$ Xbar, Figures 5a,b,c and 6a,b,c), then, bed instabilities occur only over the bar. Conversely, when $\mathrm{Xbr}<\mathrm{Xbar}$ (Figures $5 \mathrm{~d}$ and $6 \mathrm{~d}$ ), then the bottom patterns develop at the breaking location (close to the shore) and not over the 
bar. It should be remarked, however, that for the larger wave height and bar distance cases (Figures $5 \mathrm{c}$ and $6 \mathrm{c}$ ) there appears both transverse bars over the longshore bar and nearer the shore (although, at a smaller scale). These secondary bed-patterns are related with a second wave breaking near the shore.

a)

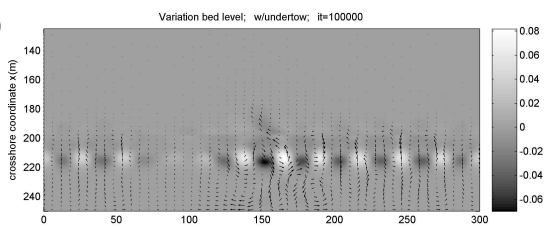

b)

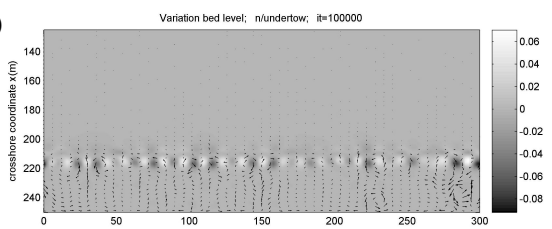

c)

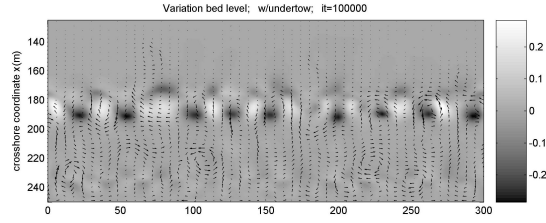

d)

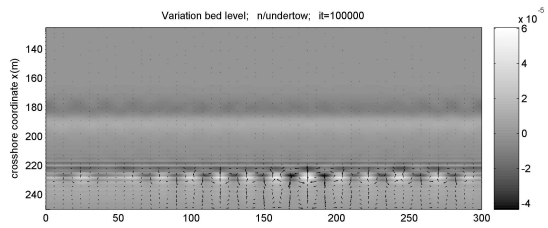

Figure 6. Bed variations and instantaneous current velocities, for the four initial conditions given by: a) $\mathrm{Xb}=40 \mathrm{~m}, \mathrm{H}=1.0 \mathrm{~m}$; b) $\mathrm{Xb}=40 \mathrm{~m}, \mathrm{H}=0.5 \mathrm{~m}$; c) $\mathrm{Xb}=70 \mathrm{~m}, \mathrm{H}=1.0 \mathrm{~m}$; d) $\mathrm{Xb}=70 \mathrm{~m}, \mathrm{H}=0.5 \mathrm{~m}$.

The results also show that for the cases with larger wave heights the circulation pattern is reinforced, causing increased sediment transport fluxes and bed-level growth rates, forming more robust periodic features (Figures $6 \mathrm{a}, \mathrm{c})$. The result is bed contours with larger shoals and pools. This applies to all cases shown here, and is even more noticeable when the undertow is included.

\section{Conclusions}

In this paper, we have predicted the formation of periodic nearshore bedforms (longitudinal, oblique, and transverse bars) in a barred beach, by means of the recently developed morphodynamic model M-SHORECIRC (Fachin \& Sancho, 2004). This model was applied here to study the effects that the wave direction and energy, and the undertow have on the predicted bed-patterns. Although M-SHORECIRC can solve the quasi-3D hydrodynamic equations, we have set it up here to solve the 2D-horizontal equations. Furthermore, we included an optional simplified mechanism of accounting for the undertow in the sediment flux computation, and resulting sediment balance equation.

It is shown that the present results agree with those of Calvete et al. (2002) using a different sediment transport model, strengthening the fact that the 
present simple formulation (Soulsby-Van Rijn model) is able to compute reasonable sediment fluxes. For the same set of conditions, we obtain the development of transverse bars identical to those of Calvete et al. (2002), but at faster growing rates. These large growth-rates are partially due to the fact that the slope term in the Soulsby-Van Rijn formula is relatively weak to stabilize the bed-form growth.

The simulations demonstrated that an initial longshore bar tends to break up under normally incident waves, forming rip-channels as observed in Dronen \& Deigaard (2000) and Calvete et al. (2002). These bed-patterns result as natural (physical) instabilities, forced by the wave and current hydrodynamics. The effect of the morphological time-step in the development of the bedpatterns was tested, yielding insignificant differences for different time-steps. This strengthened our confidence in the model's accuracy.

A second effect that we studied was the influence of the undertow in the bed evolution. We conclude that the inclusion of the undertow in the sediment transport formula changes appreciably the distribution of the sediment fluxes across the shore and, hence, changes considerably the bed evolution, relative to the case without undertow. In particular, the undertow induces stronger bed variations, and shifts the longshore bar seawards. The bed-forms are also seen to be strongly dependent on the wave angle: normal waves produce transverse bars, and oblique waves produce a shoreward migration of the longshore bar and the formation of weak oblique bars.

As for the influence of the wave height and bar-crest to shoreline distance, we first conclude that the bed-form length scale is proportional to the surf zone width (or breakpoint to shoreline distance). Also, the larger the wave height, the more pronounced the bed-forms are. Second, bed instabilities occur only over the bar when the breakpoint distance is greater than the crest-to-shoreline distance. Conversely, when the breakpoint distance is smaller than the crest-toshoreline distance, then the bottom patterns develop at the breaking location and not over the bar.

Finally, the inclusion of other sediment transport formulas in the present model should be considered. At present, no general formula has gain the consensus within the scientific community and further research is needed in order to obtain more reliable formulations.

\section{Acknowledgments}

The research underlying in this paper was carried out in the Project "HUMOR: Human Interaction with Large Scale Coastal Morphological Evolution", 
supported by the European Community (Contract EVK3-CT-2000-00037) and LNEC. The first author has received a Ph.D. grant from the Portuguese Research Council, FCT. The authors wish to thank the discussions with Dr. A. Falqués and co-workers at the UPC.

\section{References}

Caballeria, M.; Coco, G.; Falqués, A. and Huntley, D.A. (2002). Selforganization mechanisms for the formation of nearshore crescentic and transverse sand bars. J. Fluid Mech.(2002) 465,379-410.

Calvete, D., Dodd, N. and Falqués, A. (2002). Morphological Devlopment of nearshore bed-forms. Proc. 28th Int. Conf. Coastal Engng., ASCE, Vol. 3, 3321-3332.

Christensen, E.D., Deigaard, R., Fredsøe, J. (1994). Sea bed stability on a long straight coast. Proc. 24th Int. Conf. Coastal Eng., Kobe, ASCE, Vol. 2, 1865-1879.

Deigaard, R., Drønen, N., Fredsøe, J., Jensen, J.H. and Jørgensen, M.P. (1999). A morphological stability analysis for a long straigh barred coast. Coastal Engng., 36, 171-195.

Daamgaard, J., Dodd, N., Haal, L., and Chesher, T. (2002). Morphodynamic modelling of rip channel growth. Coastal Eng., 45:199-221.

Dronen, M. and Deeigaard, R. (2000). Three-dimensional nearshore bar morphology. Proc. 25th Int. Conf. Coastal Eng.,pp 3205-3217.

Fachin, S. and F. Sancho (2004). M-SHORECIRC: A New Morphodynamical Model. International Coastal Symposium, ICS 2004.To appear in J. Coastal Res., Special Issue 39.

Falqués, A., Montoto, A. and Iranzo, V. (1996). Coastal morphodynamic instabilities. Proc. 25th Int. Conf. Coastal Engng,, Orlando, ASCE, Vol. 3, 3560-3573.

Falqués, A.; Coco, G., and Huntley, D.A. (2000). A mechanism for the generation of wave driven rhythmic patterns in the surf zone. J. Geophys. Res., 105 (C10): 24071-24087.

Kirby, J.T. and Dalrymple, R.A. (1994). Combined refraction/diffraction model REF/DIF1, Version 2.5. Res. Report CACR-94-22, Center for Applied Coastal Research, Univ. of Delaware.

Putrevu, U. and Svendsen, I.A. (1999). Three-dimensional dispersion of momentum wave-induced nearshore currents. Eur. J. Mech. Fluids, 83-101.

Soulsby, R. (1997). Dynamics of marine sand: A manual for practical applications. Thomas Telford Publications, London, $249 \mathrm{pp}$.

Svendsen, I.A.; Haas, K., and Zhao, Q. (2001). Quasi-3D Nearshore Circulation Model SHORECIRC, Version 1.3.6. Center for Applied Coastal Research, University of Delaware. 